\title{
Aplicações do diagrama emergético triangular na tomada de decisão ecoeficiente
}

\author{
Biagio F. Giannetti \\ FLÁvio A. Barrella \\ Silvia H. Bonilla \\ Cecília M. Villas Boas de Almeida \\ UNIP
}

\begin{abstract}
Resumo
Diagramas ternários aliados à análise emergética são utilizados como ferramenta de suporte à tomada de decisão. A representação gráfica dos resultados da análise emergética possibilita comparar sistemas, produtos e serviços considerando os serviços provenientes do meio ambiente e da economia, avaliar melhorias e acompanhar o desempenho de um sistema produtivo. A ferramenta gráfica é versátil e pode ser aplicada para representar o desempenho de produtos, processos ou países, em um determinado período ou ao longo do tempo. Para ilustrar o uso dos diagramas emergéticos triangulares na tomada de decisão foi empregado um exemplo hipotético e quatro retirados da literatura. Mostra-se que as propriedades dos diagramas triangulares auxiliam na avaliação da eficiência dos sistemas e sua dependência dos recursos renováveis e não renováveis. Com o auxílio dos diagramas, as interações entre sistemas produtivos e as interações entre esses sistemas e o meio ambiente podem ser imediatamente verificadas e avaliadas.
\end{abstract}

Palavras-chave

Emergia, tomada de decisão, ferramenta gráfica, indicadores de sustentabilidade, diagramas ternários.

\section{Applications of the emergetic ternary diagram for eco-efficient decision making}

\begin{abstract}
Emergetic ternary diagrams and emergy accounting are used as support tools for decision making. The graphical representation of emergy analysis permits to compare systems, products and services taking into account the environmental support, to evaluate improvements and to follow systems performance with time. The graphic tool is versatile and can ce applied to represent the performance of products, processes and even countries, within a given period or along the time. To illustrate the use of emergetic ternary diagrams to support decision making, examples taken from the literature were employed. It is shown that the diagram properties help evaluating systems efficiency, their dependence on renewable and non renewable resouces and on environmental services to absorb pollutants. With the aid of emergetic ternary diagrams, the interactions between systems and between these systems and the environment can be readly verified and evaluated.
\end{abstract}

Key words

Emergy, decision making, graphic tool, sustainability indices, ternary diagrams. 


\section{INTRODUĈ̣̃O}

As empresas, como forma de assegurar a competitividade, têm incluído entre suas prioridades a preocupação com o meio ambiente. As mudanças tiveram início nas áreas de produção e operação, onde há ainda grandes oportunidades para reduzir impactos ambientais (SARKIS, 1995; SHEN, 1995). Como conseqüência, as empresas puderam verificar que a gestão ambiental eficaz é capaz de trazer melhorias tanto para o ambiente como para a competitividade (SHEN, 1995; PORTER, 1995a e 1995b; HART, 1995; AZZONE; BERTELE, 1994; MAXWELL et al., 1997).

O estudo de sistemas ambiente-empresa inclui a consideração de diversos aspectos, bastante complexos, entre os quais pode-se citar o investimento econômico, a produção ou o consumo de energia e os possíveis danos ou benefícios que o sistema pode trazer ao local, à região e ao planeta. Vários métodos têm sido propostos para avaliar cada um destes aspectos, mas ainda não há consenso quanto à existência de um método de avaliação capaz de unificar os resultados. Pelos mesmos motivos, há ainda uma grande dificuldade para representar graficamente os resultados da análise da relação ambiente-empresa.

A análise de um produto ou processo, que inclui as interações com o meio ambiente, resulta em um inventário extenso, que pode contabilizar centenas de contribuições tanto do ambiente como da economia. A procura por representações gráficas e, também, por indicadores reflete a necessidade de reduzir ou sintetizar os resultados, prin- cipalmente quando o propósito é a tomada de decisão. A análise do sistema ambiente-empresa requer a compreensão das relações entre valores tangíveis e intangíveis, variáveis dependentes e independentes. Uma representação gráfica permitiria, portanto, visualizar as interações entre ao vários parâmetros considerados.

Vários autores têm proposto representações gráficas para integrar os resultados de avaliações do setor produtivo e suas relações com o meio ambiente (RONCHI et al., 2002; JALAL; ROGERS, 2002; HOFSTETTER et al., 2000; GOMIERO; GIAMPIETRO a e b, 2002; GERBENS-LEENES; NONHEBEL, 2000; GIAMPIETRO; MUNDA, 2000; FALCONI-BENITEZ, 2000; MARADAN, 2000). Como estas relações dependem de diversas variáveis, o gráfico mais utilizado tem sido o de representação multiobjetiva, na qual a quantidade de eixos pode variar de acordo com a necessidade ou o desejo do usuário. Os eixos podem representar vários parâmetros, que não são necessariamente contabilizados com a mesma unidade de medida, derivam de diferentes abordagens teóricas e dependem de diferentes escalas de espaço e/ou tempo. Por este motivo, a maioria das representações multiobjetivas mostra uma comparação normalizada entre diferentes sistemas ou entre um determinado sistema e um sistema ideal (Figura 1). A normalização deve refletir a importância de um determinado fluxo (de entrada ou saída) entre outros que constam do inventário, para que estes possam ser comparados, mas inclui um componente subjetivo na avaliação. A comparação entre produtos ou processos só é possível se utilizado o mesmo método de normalização,

Figura 1: Exemplos de representações multiobjetivas, em que as linhas cheias representam um sistema ideal normalizado e as linhas tracejadas os resultados de um sistema hipotético sob investigação.

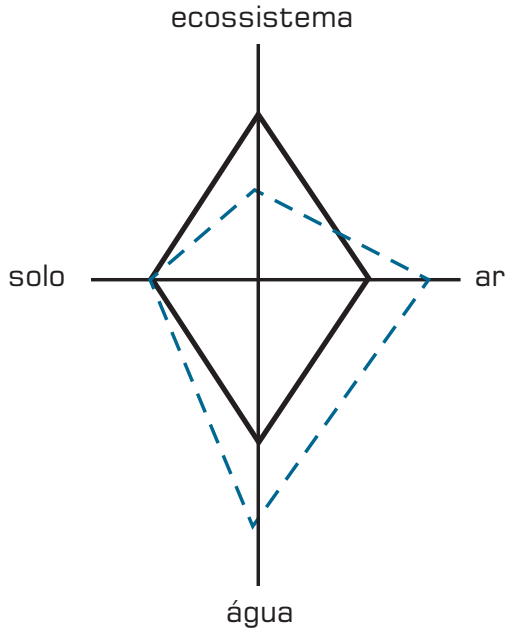

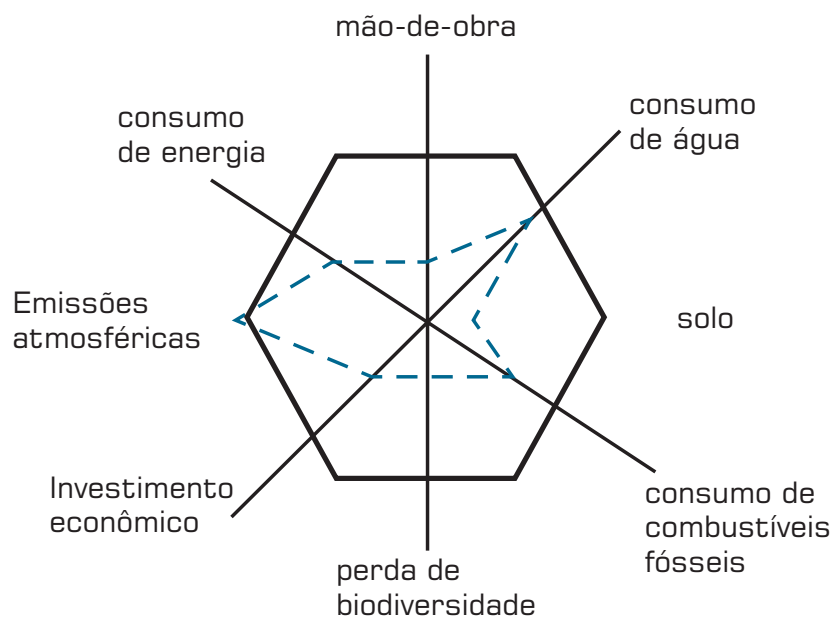


o que dificulta a comparação internacional dos resultados, dada a variedade de métodos de normalização existentes (SEPPÄLÄ; HÄMÄLÄINEN, 2001; JONSSON, 2000).

$\mathrm{O}$ presente trabalho utiliza a análise emergética para avaliar as interações empresa-ambiente com ênfase em duas vantagens da metodologia. Primeiro, todos os fluxos necessários para manter um sistema (produto ou processo) podem ser classificados em recursos renováveis $(\mathrm{R})$, não renováveis $(\mathrm{N})$ e os recursos provenientes da economia $(\mathrm{F})$, que podem ser expressos por uma mesma unidade (joules de energia solar, sej). Uma representação gráfica para a análise emergética necessita, portanto, de três eixos. Como segunda vantagem cabe ressaltar que não há necessidade de normalização dos dados para representar e interpretar a análise. para o ambiente como fonte de recursos". Neste setor, indicadores de sustentabilidade são utilizados para representar a contribuição do meio ambiente aos sistemas avaliados. A representação gráfica do setor associado ao meio ambiente contém nove subdivisões resultantes da combinação entre o fornecimento de recursos e a sustentabilidade do sistema (alto, médio ou baixo, em cada eixo).

O propósito do presente artigo é explorar a utilização dos diagramas emergéticos ternários como ferramenta gráfica de suporte à tomada de decisão, que inclui as relações entre as empresas e o meio ambiente, com o emprego da análise emergética. Cabe ressaltar que os diagramas ternários são considerados ferramentas gráficas e não uma simples representação gráfica, pois oferecem não só a possibilidade de interpretar os dados, mas também a de utilização de suas propriedades (ver metodologia).

Para ilustrar a flexibilidade da ferramenta gráfica, cinco exemplos são apresentados e discutidos. O primeiro exemplo mostra um sistema hipotético e explora todas as aplicações da ferramenta. Os outros quatro exemplos foram retirados da literatura (PANZIERI et al., 2000; ULGIATI et al., 1995;

Há, na literatura, poucos trabalhos que utilizam representações gráficas dos resultados obtidos com a análise emergética. Bastianoni (1997) considera a emergia e a exergia como aspectos complementares de um sistema. Desta forma, o quociente entre a exergia e a emergia pode indicar a eficiência de um sistema para produzir ou manter sua organização. Os resultados são mostrados em diagramas bidimensionais em que a variação de exergia é função da emergia necessária para o funcionamento do sistema. Ulgiati e Brown (1998) representam os quocientes N/F e R/F em função do investimento econômico F. Superfícies tridimensionais, que representam os indicadores emergéticos em função de N/F e R/F (funções de exploração), são utilizadas para avaliar ou simular o investimento econômico necessário para explorar recursos locais renováveis ou não renováveis. Tonon et al. (2000) utiliza as representações multiobjetivas para comparar os resultados de avaliações energéticas, exergéticas, emergéticas e econômicas. Doze variáveis foram normalizadas para comparar as contribuições do sistema econômico e do meio ambiente. $\mathrm{O}$ aspecto ambiental é representado pelos resultados da análise emergética e pelas emissões para o ambiente, o aspecto termodinâmico pela emergia e a exergia. Os resultados normalizados são comparados com um desempenho médio hipotético de cada sistema estudado. Giannantoni et al. (2002) propõem um diagrama de quatro setores que inclui a análise emergética no setor "Benefícios
SHU-LI, 1998; LEFROY; RYDBERG, 2003).

No final do artigo, as implicações da utilização de uma ferramenta que fornece informação transparente e verificável com relação ao consumo e à produção eco-compatível e sustentável.

\section{METODOLOGIA}

\section{Análise emergética}

A análise emergética não pode ser completamente explorada neste artigo, mas informações completas podem ser encontradas em: Odum, 1996; Brown e Ulgiati, 1997. Os fluxos de emergia representam três categorias de recursos: renováveis $(\mathrm{R})$, não renováveis $(\mathrm{N})$ e provenientes da economia (F). Os fluxos R e N são fornecidos pelo ambiente e não têm valor econômico, mas enquanto os recursos renováveis podem ser repostos pelo ambiente ao menos na mesma velocidade com que são consumidos, os recursos não renováveis são explorados sem que haja tempo para sua recuperação pelo ambiente. Os recursos econômicos, F, são provenientes do mercado e possuem valor em moeda. O fluxo de saída, Y, pode representar produtos, processos ou serviços. Todos os fluxos são representados com a mesma métrica (joules de emergia solar), o que evita a utilização de métodos de normalização e permite a representação gráfica direta dos resultados. A Tabela 1 mostra uma breve descrição dos indicadores que são empregados no presente trabalho. 


\section{Diagramas emergéticos ternários}

A ferramenta gráfica descrita por Giannetti et al., 2005, e Barrela et al., 2005, produz um diagrama triangular eqüilátero com três variáveis associadas a porcentagens. Desta forma, a soma de R, N e F será sempre $100 \%$. Com esta restrição, podem-se representar três variáveis em duas dimensões.

Cada vértice do triângulo está associado a um fluxo (R, $\mathrm{N}$ e F) e os lados do triângulo representam combinações binárias. Combinações de três fluxos são representadas por pontos no interior do triângulo e o valor percentual de cada fluxo é dado pela perpendicular que une o ponto e a lateral oposta ao vértice de interesse. As propriedades do diagrama triangular são mostradas na Figura 2. Uma descrição completa da ferramenta gráfica é encontrada em Barrela et al., 2005.

$\mathrm{O}$ uso das propriedades fornece informações adicionais sobre a dependência da empresa em um determinado tipo de fluxo ( $R, N$ ou F), sobre a (eco)eficiência da empresa quanto ao uso de reservas e sobre a eficiência do suporte do ambiente, necessário à operação da empresa. A ferramenta gráfica permite comparar empresas, produtos, processos e serviços, avaliar melhorias e acompanhar a performance do sistema ao longo do tempo. Com o auxílio dos diagramas, podem-se avaliar interações entre empresas ou o desempenho de um setor industrial e as interações da empresa ou do setor com o ambiente.

\section{EXEMPLOS DE APLICACÃO}

O primeiro exemplo apresentado trata um sistema hipotético. O conjunto de dados mostrados neste exemplo poderia representar um setor industrial (dez fabricantes de calçados, de peças automotivas, de eletrodomésticos, etc). Os mesmos dados poderiam, também, retratar dez países ou dez regiões de um país, dez tipos de plantio, dez tipos de tratamentos de efluentes ou dez plantas de produção de energia. Um exemplo da aplicação dos diagramas ternários para comparar plantas de produção de energia pode ser encontrado em Barrela et al., 2005. Se os fluxos de entrada (R, N e F) forem conhecidos, não há limitação para a utilização dos diagramas. Neste exemplo, são apresentadas todas as possibilidades de aplicação do diagrama emergético triangular. Os outros quatro exemplos foram retirados da literatura para oferecer um uma visão geral das possibilidades de aplicação da ferramenta. As características dos exemplos escolhidos para ilustrar o uso dos diagramas emergéticos ternários são apresentadas na Tabela 2.

Antes de apresentar as aplicações dos diagramas emergéticos é importante enfatizar o significado do índice de sustentabilidade e das linhas de sustentabilidade. O conceito de sustentabilidade é centrado na sociedade humana, na qual os sistemas industriais e agrícolas operam. O ser humano, por sua vez, tende a focalizar sua atenção em diferentes escalas, já que é mais fácil administrar e entender um sistema por partes, definindo fronteiras e limites. Entretanto, esta tendência de dividir sistemas pode levar à falsa idéia sobre a existência de um subsistema sustentável em um sistema global insustentável. Expressões do tipo "produto sustentável" ou "comunidade sustentável" devem ser interpretadas como indicações de uma contribuição benéfica do produto ou subsistema ao sistema global e não como uma declaração sobre a sustentabilidade do produto ou sistema isolado. Por definição, o índice de sustentabilidade (ESI) indica a razão entre o aproveitamento dos recursos (EYR) em relação ao impacto ambiental (ELR) (Tabela 1). Quanto melhor o aproveitamento dos recursos e menor o impacto ambiental, maior

Tabela 1: Indicadores emergéticos: símbolos, descrições e equações.

\begin{tabular}{|l|l|l|}
\hline SÍMBOLO & \multicolumn{1}{|c|}{ DESCRIÇÃ̈O } & EQUAÇÃO \\
\hline EYR & $\begin{array}{l}\text { O rendimento emergético (emergy yield ratio, EYR) é a emergia do } \\
\text { fluxo de saída Y (produto, processo ou serviço) dividida pela soma das } \\
\text { emergias do fluxo de emergia proveniente da economia (F). }\end{array}$ & $E Y R=\frac{Y}{F}=\frac{R+N+F}{F}$ \\
\hline EIR & $\begin{array}{l}\text { O investimento emergético (environmental investment ratio) é dado pela } \\
\text { razão entre a emergia do fluxo F e os fluxos de emegia provenientes do } \\
\text { ambiente, N e R. }\end{array}$ & $E I R=\frac{F}{N+R}$ \\
\hline ELR & $\begin{array}{l}\text { O indicador de carga ambiental (environmental loading ratio) mostra a } \\
\text { razão entre os fluxos de investimento econômico e de recursos não } \\
\text { renováveis e a emergia associada ao fluxo de recursos renováveis. }\end{array}$ & $E L R=\frac{N+F}{R}$ \\
\hline ESI & $\begin{array}{l}\text { O índice de sustentabilidade (sustainability index) agrega o rendimento } \\
\text { emergético e a carga ambiental. Maior será a sustentabilidade de um } \\
\text { sistema com alto rendimento e baixo impacto ambiental. }\end{array}$ & $E S I=\frac{E Y R}{E L R}=\frac{\frac{Y}{F}}{\frac{N+F}{R}}$ \\
\hline
\end{tabular}


será o índice de sustentabilidade, ou seja, maior será a contribuição do produto para a sustentabilidade da biosfera.

\section{Exemplo 1: Hipotético}

O sistema hipotético é composto por dez subsistemas (empresas) com diferentes fluxos de entrada de emergia (Tabela 3). Com os valores dos fluxos de entrada de emergia é possível calcular as porcentagens associadas às entradas de recursos renováveis, não renováveis e vindos da economia. A Tabela 3 apresenta os indicadores calculados com os valores da Tabela 4.

Admitindo que os subsistemas designados de 1 a 10 representam distintos processos de produção de um determinado setor industrial, obtém-se das Tabelas 4 e 5 uma série de informações que podem ser utilizadas para comparar os pro- cessos de produção considerados. Por exemplo, os processos 2 e 3 utilizam a mesma proporção de recursos renováveis (Tabela 3). O rendimento emergético (EYR) e o índice de sustentabilidade (ESI) do processo 2 são melhores que os do processo 3 (Tabela 4), mas o índice de carga ambiental é o mesmo para os dois processos. Os recursos fornecidos pela economia para o processo 2 são três vezes menores que aqueles fornecidos para o processo 3 , mas o processo 2 usa seis vezes mais recursos não renováveis que o processo 3 (Tabela 3). Este tipo de comparação torna-se cada vez mais complicado à medida que o número de processos aumenta e, mesmo com o cálculo dos índices que sintetizam os resultados, a tomada de decisão baseada neste tipo de análise não é uma tarefa fácil e a interpretação dos dados torna-se exaustiva à medida que o número de subsistemas aumenta.

Figura 2: Propriedades dos diagramas ternários como ferramenta de suporte à análise emergética.

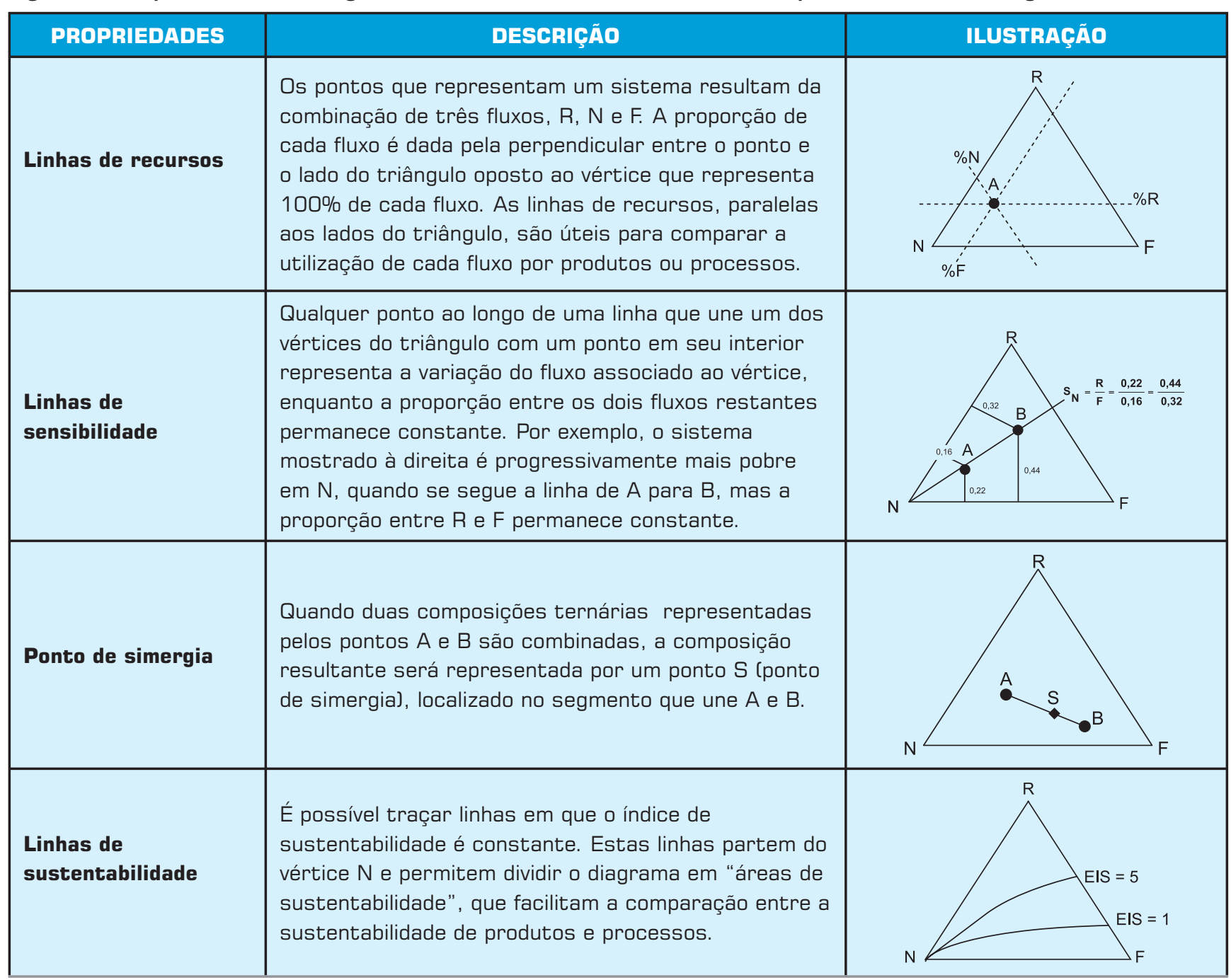

Fonte: Barrela et al., 2005. 
Por outro lado, a representação dos subsistemas 2 e 3 no diagrama emergético ternário permite a imediata visualização dos resultados e facilita a comparação entre os processos (Figura 3a). Nota-se que os processos 2 e 3 utilizam a mesma proporção de recursos renováveis $(\% \mathrm{R}=60 \% \mathrm{sej} / \mathrm{sej})$, mas que a sustentabilidade do subsistema 2 é superior à do subsistema 3 .

Na Figura 3b os processos 1, 2, 3, 4, 6 e 8 são apresentados juntamente com as linhas de recursos $\mathrm{R}=0,6, \mathrm{~N}=0,05$ e $\mathrm{F}$ $=0,2$. As linhas de sustentabilidade para ESI $=1$ e ESI $=5$ também são mostradas. É fácil notar que os processos 1, 3 e 8 usam a mesma porcentagem de recursos locais não renováveis, pois estão na mesma linha paralela ao lado RF $(\% \mathrm{~N}$ $=5 \% \mathrm{sej} / \mathrm{sej}$ ) do triângulo. $\mathrm{O}$ índice de sustentabilidade do processo 1 é o mais alto, pois este ponto é o que se localiza acima de todos os outros no diagrama. O processo 3 apresenta uma contribuição para a sustentabilidade em médio prazo, já que está localizado entre as linhas de ESI $=1$ e $\mathrm{ESI}=5$ (BROWN; ULGIATI, 1997), enquanto o processo 8, localizado abaixo da linha ESI = 1, não poderá sustentar-se em operação por longo prazo. Da mesma forma, observa-se que os processos 6 e 8 empregam a mesma proporção de recursos renováveis $(\% \mathrm{R}=20 \% \mathrm{sej} / \mathrm{sej})$, mas que o processo 6 contribui mais para a sustentabilidade do setor, já que utiliza menor quantidade de recursos da economia e encontra-se na região $1<\mathrm{ESI}<5$.

Os processos 4 e 6 também podem ser comparados no diagrama da figura 3b. Ambos os processos utilizam a mesma porcentagem de recursos da economia (linha paralela ao lado $\mathrm{RN}$ do diagrama, $\% \mathrm{~F}=20 \% \mathrm{sej} /$ sej) para sua operação,

Tabela 2: Características dos exemplos escolhidos para aplicação dos diagramas emergéticos ternários.

\begin{tabular}{|c|c|c|c|c|}
\hline EXEMPLO & SETOR ESTUDADO & LOCALIZAÇÃO & TEMPO/ANOS & TIPO DE ANÁLISE \\
\hline 1 & Hipotético * & & 1 & comparativo \\
\hline 2 & Agricultura & EUA & 10 & tendência \\
\hline 3 & Agricultura & Itália & 1 & tendência \\
\hline 4 & Economia & Taiwan & 4 & tendência \\
\hline 5 & Agricultura & Austrália & 1 & comparativo \\
\hline
\end{tabular}

"Setor industrial composto por dez empresas.

Tabela 3: Valores hipotéticos de fluxo emergético anual para 10 subsistemas e as porcentagens associadas às entradas de recursos.

\begin{tabular}{|c|c|c|c|c|c|c|c|}
\hline SUBSISTEMA & $\begin{array}{c}\text { EMERGIA TOTAL / } \\
\text { (SEJ / ANO) }\end{array}$ & R / (SEJ) & $\%$ R & N / (SEJ) & \%N & F / (SEJ) & \%F \\
\hline 1 & $6,4 \times 10^{20}$ & $5,1 \times 10^{20}$ & 80 & $3,2 \times 10^{19}$ & 05 & $9,6 \times 10^{19}$ & 15 \\
\hline 2 & $8,0 \times 10^{19}$ & $6,4 \times 10^{19}$ & 60 & $0,4 \times 10^{19}$ & 30 & $1,2 \times 10^{19}$ & 10 \\
\hline 3 & $7,5 \times 10^{19}$ & $4,5 \times 10^{19}$ & 60 & $3,7 \times 10^{18}$ & 05 & $2,7 \times 10^{19}$ & 35 \\
\hline 4 & $6,0 \times 10^{19}$ & $2,4 \times 10^{19}$ & 40 & $2,4 \times 10^{19}$ & 40 & $1,2 \times 10^{19}$ & 20 \\
\hline 5 & $5,0 \times 10^{19}$ & $2,0 \times 10^{19}$ & 40 & $5,0 \times 10^{18}$ & 10 & $2,5 \times 10^{19}$ & 50 \\
\hline 6 & $5,5 \times 10^{19}$ & $1,1 \times 10^{19}$ & 20 & $3,3 \times 10^{19}$ & 60 & $1,1 \times 10^{19}$ & 20 \\
\hline 7 & $2,4 \times 10^{20}$ & $4,8 \times 10^{18}$ & 20 & $4,8 \times 10^{19}$ & 20 & $1,4 \times 10^{20}$ & 60 \\
\hline 8 & $7,2 \times 10^{19}$ & $7,2 \times 10^{18}$ & 20 & $3,6 \times 10^{18}$ & 05 & $5,4 \times 10^{19}$ & 75 \\
\hline 10 & $7,8 \times 10^{19}$ & $7,8 \times 10^{18}$ & 10 & $6,2 \times 10^{19}$ & 80 & $7,8 \times 10^{18}$ & 10 \\
\hline
\end{tabular}


mas a diferença no uso de recursos renováveis determina a maior sustentabilidade do processo 4 , localizado mais próximo do vértice $\mathrm{R}$.

Na Figura 4 mostra-se a utilização das linhas de sensibilidade (ver descrição na Tabela 2). A linha que une o vértice $\mathrm{N}$ ao ponto 9 passa, também, pelo ponto 6. Qualquer ponto ao longo da linha representa um processo que opera com quantidades de recursos não renováveis progressivamente menores, na direção de 9 a 6 , mas com a proporção constante entre R e F. Desta forma, seria possível melhorar a sustentabilidade do processo 9, diminuindo a quantidade de recursos não renováveis empregada e mantendo a proporção entre o investimento da economia e o uso de recursos renováveis.
É, também, fácil notar no diagrama que um decréscimo no uso de recursos da economia no processo 8 pode aumentar sua sustentabilidade de forma a torná-lo equivalente ao processo 5. Da mesma forma, a linha que une o vértice $\mathrm{R}$ ao processo 7 indica que para aumentar sua sustentabilidade deve-se dar atenção ao uso de recursos renováveis.

As linhas de sensibilidade podem mostrar claramente aos responsáveis pelas tomadas de decisão uma forma de alcançar alvos em que tanto os fatores econômicos como os ambientais têm importância. Retomando a comparação entre os processos 6 e 9, dois pontos podem ser enfatizados. Primeiro, se o processo 6 existe, deve haver uma forma de produzir ou uma tecnologia para melhorar o desempenho

Tabela 4: Indicadores emergéticos.

\begin{tabular}{|c|c|c|c|c|}
\hline SUBSISTEMA & ELR & EYR & EIR & ESI \\
\hline 1 & 0,25 & 6,67 & 0,18 & 26,67 \\
\hline 2 & 0,67 & 10,00 & 0,11 & 15,00 \\
\hline 3 & 0,67 & 2,86 & 0,54 & 4,29 \\
\hline 4 & 1,50 & 5,00 & 1,00 & 1,33 \\
\hline 5 & 1,50 & 2,00 & 0,25 & 1,25 \\
\hline 6 & 4,00 & 5,00 & 1,50 & 0,42 \\
\hline 7 & 4,00 & 1,67 & 3,00 & 0,33 \\
\hline 8 & 4,00 & 1,33 & 0,11 & 1,11 \\
\hline 9 & 9,00 & 10,00 & 4,00 & 0,14 \\
\hline
\end{tabular}

Figura 3: Representação de alguns dos processos hipotéticos mostrados na Tabela 4.
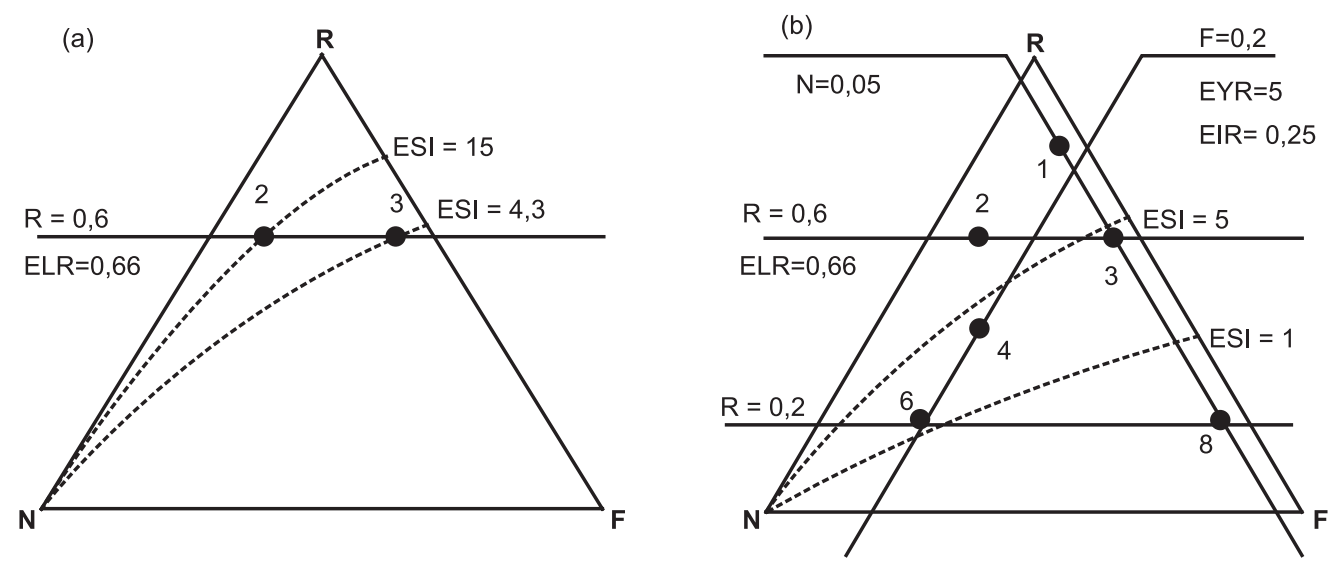
do processo 9 para que este, no mínimo, se equipare em desempenho ao processo 6 . Segundo, as linhas de sensibilidade indicam uma hierarquia para a ação. Em vez de mudar as três variáveis $(\mathrm{R}, \mathrm{N}$ e $\mathrm{F})$ de forma aleatória para obter melhorias no processo 9, deve-se priorizar a redução do uso de recursos não renováveis.
Os diagramas da Figura 5 mostram a aplicação de outra propriedade: o ponto de simergia (ver descrição na Tabela 2). Este ponto representa o conjunto resultante da combinação entre vários subsistemas. O ponto de simergia é utilizado para determinar as características do conjunto, neste caso composto pelos processos $1,2,6,7$ e 10, quanto ao uso de

Figura 4: llustração do uso das linhas de sensibilidade nos diagramas emergéticos ternários.

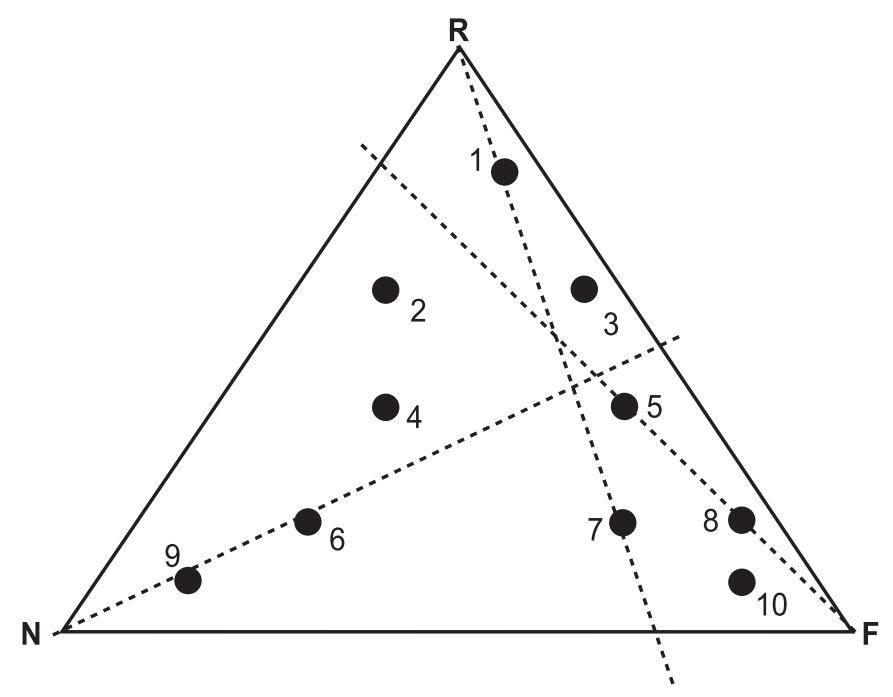

Figura 5: Diagramas emergéticos ternários ilustrando: (a) o ponto simérgico ( $\square$ ] representa o conjunto formado pelos subsistemas 1, 2, 6, 7 e 10, considerando que cada um tem a mesma produção; e (b) o ponto simérgico $(\square$ ) representa o conjunto formado pelos subsistemas 1, 2, 6, 7 e 10, considerando a produção de cada um.
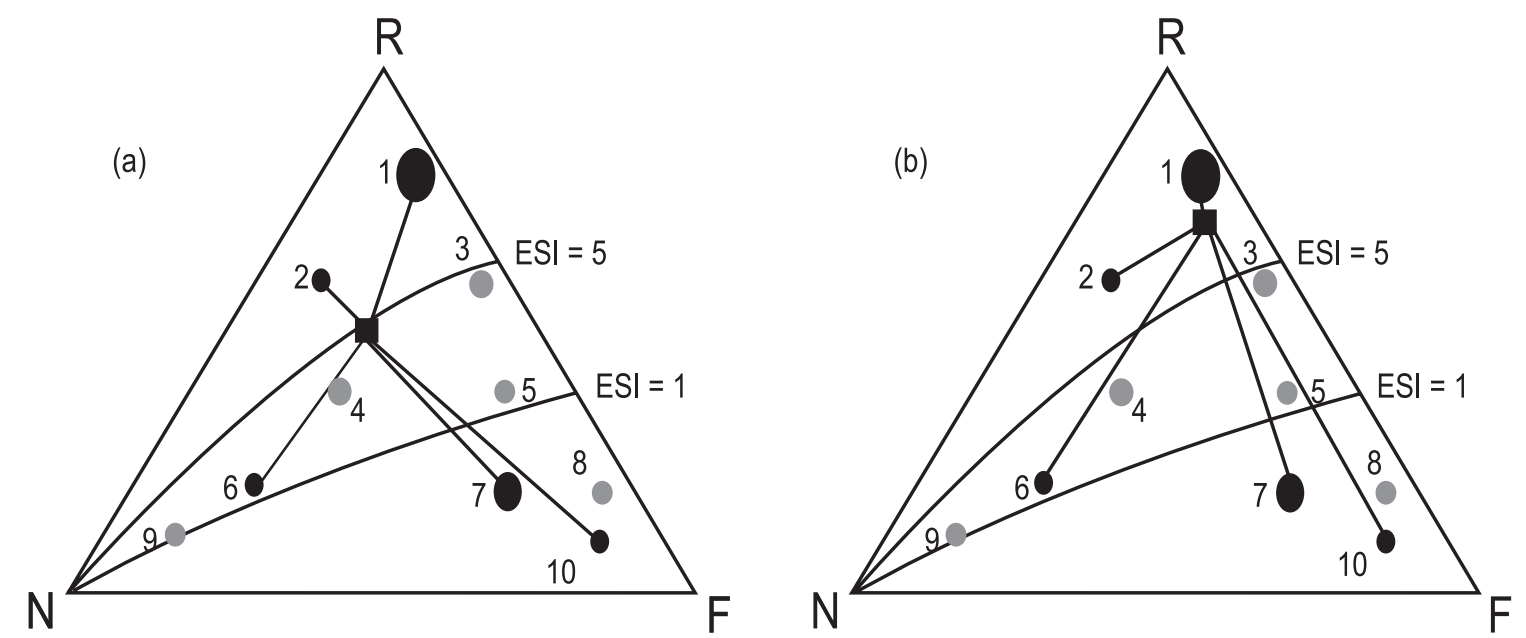
recursos provenientes do meio ambiente $(\mathrm{R}$ e N) e da economia $(\mathrm{F})$. A localização do ponto de simergia no diagrama permite a rápida visualização da interação do conjunto com o meio ambiente. Na figura 5a, em que se considera que a quantidade de produto é a mesma para todos os processos indicados, a posição do ponto de simergia mostra que o índice de sustentabilidade do conjunto tem valor entre 1 e 5 , o que indica que quando estes subsistemas operam em conjunto são sustentáveis em médio prazo. Como a quantidade de produto em cada subsistema pode variar drasticamente, também é possível levar em conta a capacidade de cada unidade de produção, que corresponde ao tamanho dos pontos no diagrama. $O$ ponto de simergia mostrado na figura $4 \mathrm{~b}$ foi obtido admitindo-se que os processos 2, 6 e 10 produzem quantidades iguais. A quantidade produzida pelo processo 1 é oito vezes maior e o processo 7 tem capacidade para produzir três vezes mais que o processo 2. Observa-se que, mesmo quando o processo 7 que tem péssimo desempenho ambiental (ESI =0,42) participa do conjunto, sua associação com as outras quatro unidades de produção (especialmente a 1) garante a sustentabilidade do conjunto em longo prazo $(\mathrm{ESI}=7,2)$. O diagrama evidencia que as empresas 1,2 , 6, 7 e 10, se consideradas em conjunto, devem investir na implantação de processos como o 1 ou o 2 para futuras expansões do sistema.

\section{Exemplo 2}

O artigo de Ulgiati e Brown, 1998 (Monitoring patterns of sustainability in natural and man-made ecosystems) destaca que os indicadores emergéticos podem ser úteis para monitorar as oscilações de um sistema, para prever seu comportamento e para adotar políticas adequadas no sentido de contribuir para a sustentabilidade. Com este objetivo, os autores apresentam as funções de exploração N/F e R/F, que são representadas em superfícies tridimensionais em função de ELR, EYR e ESI para monitorar ou simular condições em que a quantidade de recursos que entram em um sistema é mudada. As superfícies tridimensionais podem ser utilizadas para avaliar a quantidade de investimento necessário para explorar um recurso local (renovável ou não renovável).

Entre os diversos exemplos mostrados no artigo, selecionou-se um que mostra a variação dos indicadores emergéticos da produção de milho, nos Estados Unidos, de 1945 a 1994. A função de exploração R/F e o índice de sustentabilidade apresentaram um decréscimo acentuado de 1945 até 1980, mantendo-se com valores estáveis até 1994 (ESI entre $0,37$ e 0,34$)$. A razão entre N/F aumentou até o final da década de 1980 e estabilizou-se em aproximadamente 0,3 .

Para utilizar os diagramas emergéticos ternários foram calculadas as porcentagens dos fluxos R, N e F empregando os dados apresentados no artigo de Ulgiati e Brown, 1998 (Tabela 5). O diagrama emergético ternário que representa os dados da tabela 4 é mostrado na Figura 6.

A diminuição do índice de sustentabilidade pode ser imediatamente verificada, assim como sua estabilização após 1980 (Figura 6). A observação do diagrama traz informações adicionais. A linha de recursos $F=0,6$ evidencia que a fração que corresponde ao investimento econômico não variou significativamente ao longo dos anos, de 1945 a 1970. O rendimento emergético (EYR) e o investimento emergético (EIR) mantiveram-se em valores próximos de 1,6 e 1,5, respectivamente. Apesar de um investimento da economia

Tabela 5: Porcentagens de recursos renováveis $(R)$, não renováveis $(N)$ e pagos $[F]$ utilizados na produção de milho nos Estados Unidos, 1945-1994.

\begin{tabular}{|c|c|c|c|}
\hline ANO & $\% \mathbf{R} /$ (SEJ/SEJ) & $\%$ N / (SEJ/SEJ) & \% F / (SEJ/SEJ) \\
\hline 1945 & 40 & 1 & 59 \\
\hline 1950 & 36 & 11 & 57 \\
\hline 1954 & 32 & 13 & 58 \\
\hline 1959 & 29 & 16 & 58 \\
\hline 1964 & 26 & 18 & 60 \\
\hline 1970 & 22 & 22 & 56 \\
\hline 1975 & 22 & 20 & 62 \\
\hline 1980 & 18 & 18 & 64 \\
\hline 1989 & 18 & 13 & 68 \\
\hline 1994 & 19 & & 9 \\
\hline
\end{tabular}

Fonte: Ulgiati e Brown, 1998. 
$(\% \mathrm{~F})$ ao redor de $60 \% \mathrm{sej} / \mathrm{sej}$ durante todo o período, a carga ambiental (ELR) aumentou mais de $20 \% \mathrm{sej} / \mathrm{sej}$ e a fração de recursos renováveis utilizada diminuiu de 0,40 para 0,18 , reduzindo o valor do índice de sustentabilidade, EIS, a um terço de seu valor inicial.

Este exemplo mostra que é possível monitorar sistemas ou setores ao longo do tempo com a utilização dos diagramas emergéticos ternários. Infelizmente, a análise mostrou um decréscimo do ESI, o que indica, neste caso, que as inovações tecnológicas aplicadas para aumentar a produtividade nem sempre levam em conta a sustentabilidade ambiental.

\section{Exemplo 3}

Neste exemplo, utiliza-se um artigo que avalia como o índice de sustentabilidade do plantio da soja na região da Toscana, na Itália (Importance of the Bradhyrizobium japonicum symbiosis for the sustainability of soybean cultivation, PANZIERI et al.., 2000) varia em função da troca de tecnologia. Os autores comparam o plantio de soja tradicional, que utiliza fertilizantes químicos, com o uso de inoculação de uma bactéria, Bradhyrizobium japonicum, para fixar nitrogênio no solo. O estudo emprega os indicadores emergéticos para avaliar não só a contribuição do setor econômico, mas também o impacto ambiental causado por esta atividade da agricultura. Dois tipos de cultivo de soja foram estudados: (1) com a utilização de fertilizantes químicos para suprir a necessidade de nitrogênio do solo e (2) com a utilização da bactéria Bradhyrizobium japonicum. Os resultados deste estudo foram comparados com outros da literatura que tratam de diversos cultivos na Itália (ULGIATI et al., 1995; PANZIERI, 1995). Os valores de EYR, EIR e ESI e as porcentagens de \%R, \%N e \%F são mostrados na Tabela 6.

A figura 7 a mostra a representação do cultivo da soja que emprega fertilizantes químicos (1), com $\mathrm{ESI}=1,6$, e com a inoculação da bactéria (2), ESI $=2,5$. O índice de sustentabilidade para os dois tipos de cultivo é maior que 1 e maior que os índices de todos os outros cultivos, com exceção do ESI calculado para o plantio de forragem na região da Toscana (Figura 7b).

A linha de sensibilidade que parte do vértice $F(S F)$ e passa pelos pontos 1 (produção de soja com fertilizantes químicos) e 2 (produção de soja com utilização de bactérias) mostra que a maior diferença entre os dois tipos de cultivo é devida à contribuição da economia. A utilização de recursos nos dois casos estudados está dividida em aproximadamente $5 \% \mathrm{sej} / \mathrm{sej}$ de recursos renováveis e $3 \% \mathrm{sej} / \mathrm{sej}$ de recursos não renováveis (Figura 6). $\mathrm{O}$ aumento da sustentabilidade com a utilização da bactéria está associado ao menor investimento da economia no processo de inoculação.

Ambos os tipos de cultivo de soja investigados apresentam impacto ambiental menor que o causado por outros tipos de cultivo, consideradas as produções nacionais ou

Figura 6: Diagrama emergético ternário que mostra a produção de milho nos Estados Unidos de 1945 a 1995, onde (1) 1945, (2) 1950, (3) 1954, (4) 1959, (5) 1964, (6) 1970, (7) 1975, (8) 1980, (9) 1989 e (10) 1994.

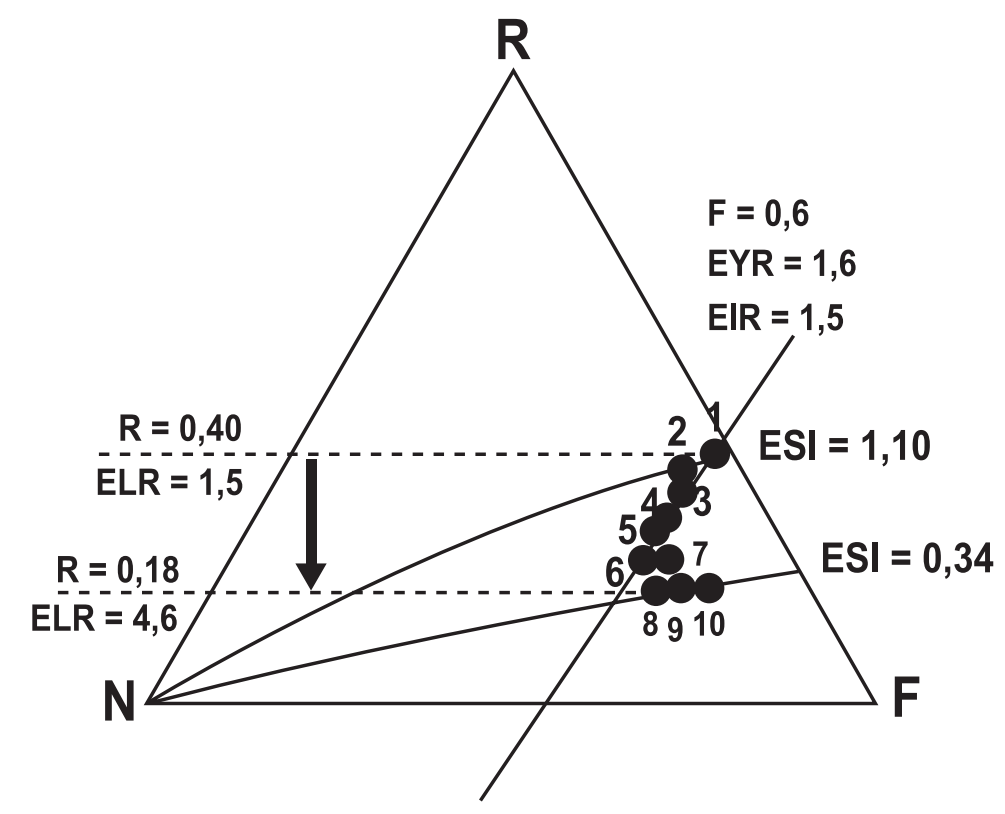


somente da região da Toscana. O valor de EYR em torno de 2 sugere que a exploração dos recursos locais é eficiente nos dois cultivos. As informações adicionais, obtidas com o auxílio do diagrama emergético ternário, mostram que todos os nove tipos de cultivo utilizam quantidades semelhantes de recursos não renováveis (Figura $7 \mathrm{~b}$ ). Desta forma, a principal diferença entre os diversos cultivos está no uso de recursos renováveis $(3,5-51,8 \%$ sej/sej) e no uso de recursos da economia (39-96\% sej/sej).

$\mathrm{O}$ índice de sustentabilidade varia consideravelmente em função do tipo de cultivo, de 0,04 (girassol) a 4,02 (forragem, Toscana). Como a utilização de recursos não renováveis é praticamente a mesma, a variação do índice de sustentabilidade é devida ao balanceamento entre as entradas renováveis

Tabela 6: Indicadores emergéticos para o plantio da soja utilizando dois métodos de fixação de nitrogênio e para diversos cultivos na Itália.

\begin{tabular}{|c|c|c|c|c|c|c|}
\hline & ELR & EYR & ESI & $\begin{array}{c}\% \text { R / } \\
\text { [SEJ/ } \\
\text { SEJ] }\end{array}$ & $\begin{array}{c}\% \text { N / } \\
\text { [SEJ/SEJ] }\end{array}$ & $\begin{array}{l}\text { \% F / } \\
\text { [SEJ/ } \\
\text { SEJ] }\end{array}$ \\
\hline Soja (tradicional, Toscana) & 1,22 & 1,98 & 1,62 & 45 & 4 & 51 \\
\hline Soja (Bradhyrizobium japonicum, Toscana) & 0,93 & 2,32 & 2,49 & 52 & 5 & 43 \\
\hline Milho (Itália) & 5,63 & 1,19 & 0,21 & 15 & 1 & 84 \\
\hline Milho (Toscana) & 2,47 & 1,53 & 0,62 & 29 & 6 & 65 \\
\hline Girassol (Itália) & 27,88 & 1,04 & 0,04 & 4 & 1 & 95 \\
\hline Girassol (Toscana) & 1,89 & 1,64 & 0,87 & 35 & 4 & 61 \\
\hline Cereais (Toscana) & 3,02 & 1,33 & 0,44 & 25 & 0 & 75 \\
\hline Forragem (Itália) & 1,45 & 1,76 & 1,21 & 41 & 2 & 57 \\
\hline Forragem (Toscana) & 0,64 & 2,57 & 4,02 & 61 & 0 & 39 \\
\hline
\end{tabular}

Fonte: Ulgiati et al.,1995; Panzieri, 1995.

Figura 7: Diagramas emergéticos ternários representando (a) produção de soja com fertilizantes químicos (1) e com inoculação de Bradhyrizobium japonicum (2) e (b) milho na Itália (3), milho na Toscana (4), girassol na Itália (5), girassol na Toscana (6), cereais na Toscana (7), forragem na Itália (8) e forragem na Toscana (9).
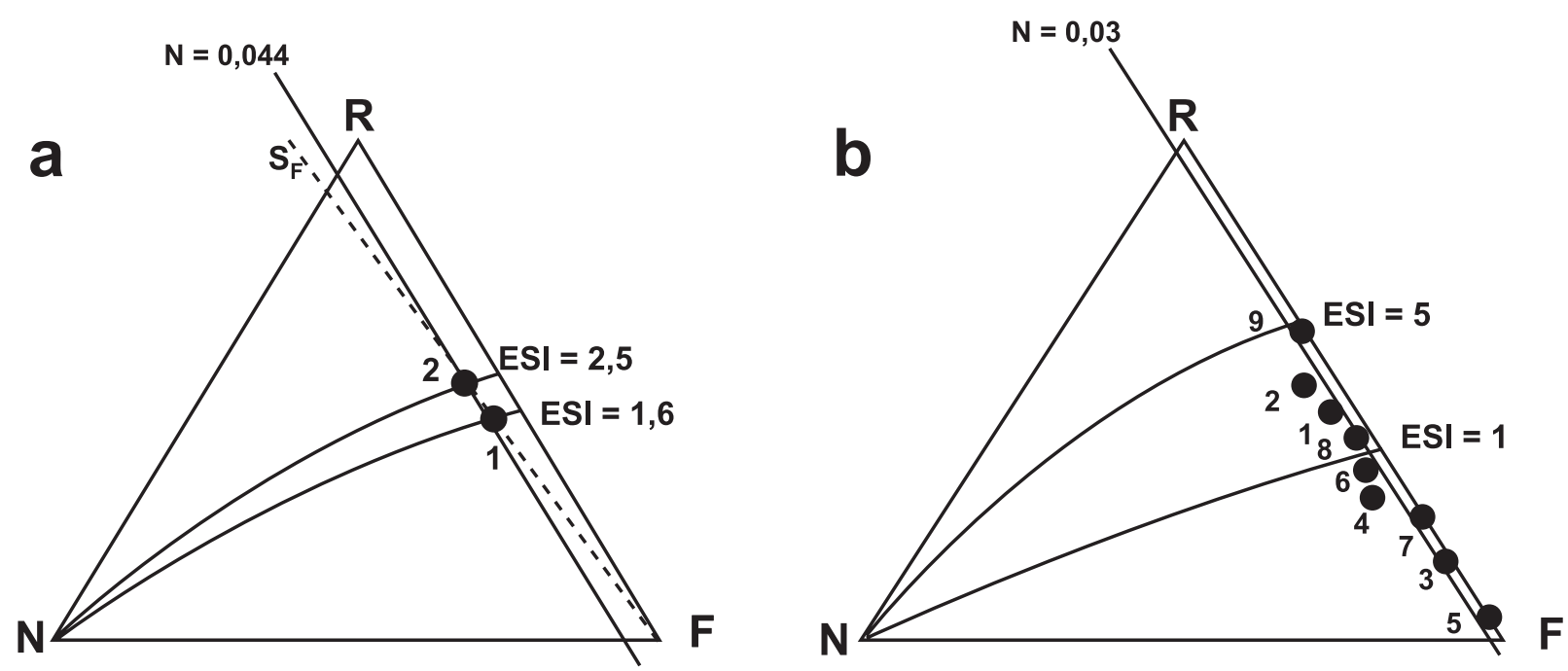
e as do setor econômico. Desta forma, conclui-se que os sistemas que melhor exploram os recursos locais e têm maior EYR apresentam maior índice de sustentabilidade.

\section{Exemplo 4}

Neste artigo, os autores pretendiam verificar se a análise emergética pode auxiliar no planejamento urbano, de forma a contribuir para o desenvolvimento de cidades sustentáveis (Urban ecosystems, energetic hierarchies, and ecological economics of Taipei metropolis, SHU-LI, 1998). A análise emergética foi empregada para avaliar os fluxos de recursos utilizados por Taiwan com o propósito de mostrar que a mesma discussão poderia ser aplicada no estudo de centros urbanos. O artigo apresenta dados de 1960, 1970, 1980 e 1990 que mostram a evolução do uso de recursos por Taiwan e discute os estágios de desenvolvimento em cada período. A Tabela 7 mostra os recursos utilizados por Taiwan e os indicadores emergéticos calculados para cada ano considerado.

A Figura 8 mostra o diagrama emergético ternário construído com os dados referentes às entradas de recursos em Taiwan (Tabela 7). Como a emergia total do país aumentou ao longo das quatro décadas, o tamanho dos pontos foi ajus-

Tabela 7: Entradas de recursos em Taiwan referentes a 1960, 1970, 1980 e 1990 e indicadores emergéticos calculados para cada ano.

\begin{tabular}{|l|c|c|c|c|}
\hline & $\mathbf{1 9 6 0}$ & $\mathbf{1 9 7 0}$ & $\mathbf{1 9 8 0}$ & $\mathbf{1 9 9 0}$ \\
\hline Recursos renováveis / sej & $2,13 \times 10^{22}$ & $2,13 \times 10^{22}$ & $2,13 \times 10^{22}$ & $2,13 \times 10^{22}$ \\
\hline Recursos não renováveis / sej & $1,05 \times 10^{22}$ & $2,32 \times 10^{22}$ & $2,86 \times 10^{22}$ & $4,02 \times 10^{22}$ \\
\hline Recursos da economia / sej & $7,45 \times 10^{21}$ & $2,79 \times 10^{22}$ & $1,22 \times 10^{23}$ & $1,52 \times 10^{23}$ \\
\hline Emergia total / sej & $4,93 \times 10^{22}$ & $7,24 \times 10^{22}$ & $1,72 \times 10^{23}$ & $2,14 \times 10^{23}$ \\
\hline EYR & 6,61 & 2,59 & 1,41 & 1,40 \\
\hline EIR & 0,18 & 0,63 & 2,44 & 2,48 \\
\hline ELR & 1,32 & 2,40 & 7,06 & 9,04 \\
\hline ESI & 5,03 & 1,08 & 0,20 & 0,16 \\
\hline
\end{tabular}

Fonte: Shu-Li, 1998.

Figura 8: Diagrama emergético ternário representando Taiwan em 1960 (1), 1970 (2), 1980 (3) e 1990 (4).

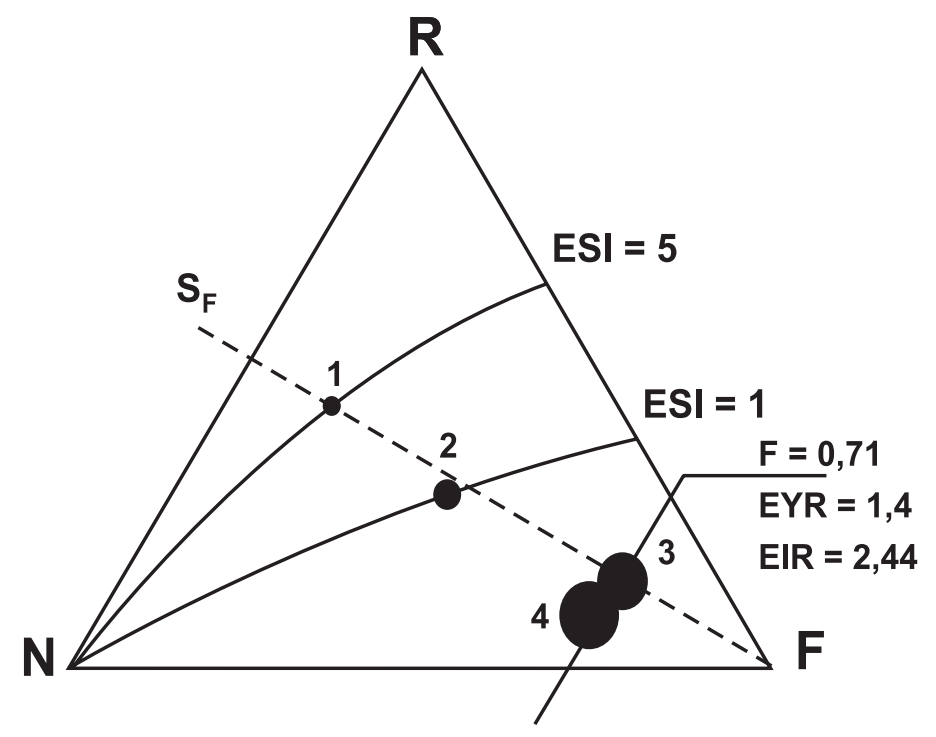


tado para representar o aumento, isto é, o tamanho dos pontos mostrados no diagrama é proporcional ao valor da emergia total (Y) de cada ano. Os pontos 1, 2 e 3 estão localizados sobre a linha de sensibilidade SF, o que indica que houve aumento da fração de investimento econômico até 1980, mas que a proporção entre o uso de recursos renováveis e não renováveis se manteve constante no período. Em 1990, nota-se que o investimento econômico não aumentou, porém houve uma diminuição do uso de recursos renováveis com conseqüente aumento do uso de não renováveis (ponto 4).
O diagrama emergético ternário mostra que a transição de Taiwan de país pouco desenvolvido para altamente industrializado ocorreu em 1980, por meio de grande investimento do setor econômico, enquanto que a proporção entre o uso de recursos renováveis e não renováveis se manteve praticamente constante (notar que os pontos se localizam sobre a linha SF). De 1980 a 1990, a fração de recursos vindos da economia manteve-se em aproximadamente $71 \%$ sej/sej, mas um decréscimo no uso de recursos renováveis acompanhado de um aumento na utilização de recursos não renováveis fez com que houvesse ainda uma pequena diminuição no valor do índice de sustentabilidade.

Como a área do país permaneceu a mesma nestas quatro décadas, o aumento do tamanho dos pontos no diagrama pode ser interpretado como um aumento da atividade no período, isto é, um aumento da densidade emergética associada à autoorganização do sistema.
Após 40 anos, a fração de recursos renováveis diminuiu para um quarto de seu valor em $1960\left(\% \mathrm{R}_{1960}=\right.$ $43 \%$ sej $/$ sej, $\% R_{1970}=29 \%$ sej $/$ sej, $\% R_{1980}=12 \%$ sej $/$ sej e $\% R_{1990}=10 \%$ sej $/$ sej), a fração utilizada de recursos não renováveis também decresceu no período $\left(\% \mathrm{~N}_{1960}=\right.$ $42 \% \mathrm{sej} / \mathrm{sej}, \% \mathrm{~N}_{1970}=32 \% \mathrm{sej} / \mathrm{sej}, \% \mathrm{~N}_{1980}=17 \% \mathrm{sej} / \mathrm{sej}$ e $\% \mathrm{~N}_{1990}=19 \% \mathrm{sej} / \mathrm{sej}$ ), mas a fração de recursos provenientes da economia aumentou substancialmente $\left(\% \mathrm{~F}_{1960}\right.$ $=15 \% \mathrm{sej} / \mathrm{sej}, \% \mathrm{~F}_{1970}=39 \% \mathrm{sej} / \mathrm{sej}, \% \mathrm{~F}_{1980}=71 \% \mathrm{e} \% \mathrm{~F}_{1990}$ $=71 \%$ sej/sej).

A localização dos pontos no diagrama mostra a mudança no uso de recursos do país, o que está de acordo com a história do desenvolvimento de seu sistema econômico. Em 1960, Taiwan era um país pouco desenvolvido e seu desenvolvimento econômico se deu com o auxílio dos Estados Unidos. A contribuição dos recursos renováveis ( $\%$ R sej/sej) para o país era equivalente a $43 \% \mathrm{sej} / \mathrm{sej}$ da emergia total. Por outro lado, a porcentagem de recursos da economia era de apenas $15 \% \mathrm{sej} / \mathrm{sej}$ da emergia total. O índice de sustentabilidade, $\mathrm{ESI}_{1960}=5,03$, mostra que a exploração dos recursos locais era eficiente e que o impacto ambiental causado pelas atividades no país era pequeno. Nos anos 1960, a fim de expandir o comércio com outros países, Taiwan aumentou seus fluxos de importação e exportação para valores três vezes maiores que os praticados no início da década. Em 1970, o índice de sustentabilidade caiu para $\mathrm{ESI}_{1970}=1,08$, indicando que a política de desenvolvimento adotada levou o país a uma condição em que a sustentabilidade a longo prazo não era mais possível. Em 1980 e 1990, o país foi classificado como altamente industrializado com índices de sustentabilidade de 0,20 e 0,16 , respectivamente.

\section{Exemplo 5}

Lefroy e Rydberg (2003) analisaram três processos de cultivo no sudoeste da Austrália e os compararam quanto aos seus efeitos sobre o solo arenoso por meio do cálculo dos índices emergéticos. As três culturas são: (1) sistema de rotação tremoço/trigo, denominado sistema convencional; (2) sistema de cultivo em ruelas, em que se faz a rotação tremoço/trigo entre fileiras de tagasaste, uma árvore de forragem (550 árvores por hectare); e (3) plantação densa de tagasaste (2.300 árvores por hectare). Os fluxos de energia e materiais entre o ambiente e os sistemas sob investigação foram identificados e contabilizados. Os valores dos fluxos associados às fontes de recursos $\mathrm{N}, \mathrm{R}$ e $\mathrm{F}$ e dos índices emergéticos são mostrados na Tabela 8 .

Os resultados da comparação efetuada entre os três tipos de cultura mostraram que os maiores fluxos para o plantio de tremoço/trigo estão associados à erosão e à compra de fosfato. Neste tipo de cultivo a porcentagem de recursos renováveis é de $15 \% \mathrm{sej} / \mathrm{sej}$ e o $E L R=5,5$. A componente renovável do sistema de cultivo em ruelas é de $30 \%$ sej/sej $(E L R=2,3)$ e de $53 \%$ sej/sej na plantação densa de tagasaste $(E L R=0,7)$. A análise mostrou que a plantação de tagasaste é a mais eficiente na transformação de recursos naturais em bens e serviços e a mais lucrativa, enquanto que o cultivo de rotação tremoço/trigo é o menos eficiente no uso de recursos e o menos lucrativo. A Tabela 8 mostra os fluxos de recursos de cada tipo de cultivo e os índices calculados para os três sistemas de cultivo.

A Figura 9 mostra os três sistemas de cultivo representados no diagrama emergético ternário. Nota-se que o sistema 
que utiliza rotação anual de tremoço e trigo tem o menor índice de sustentabilidade (ESI $=0,58)$ e a menor fração de entradas renováveis $(\% R=15,5 \% \mathrm{sej} / \mathrm{sej})$, enquanto que o maior valor para o índice de sustentabilidade é associado à plantação de tagasaste $(\mathrm{ESI}=3,1)$, com uma fração de recursos renováveis maior que $50 \% \mathrm{sej} / \mathrm{sej}$. O cultivo em ruelas ocupa uma posição intermediária, com ESI =0,99 e $\% \mathrm{R}=30,2 \% \mathrm{sej} / \mathrm{sej}$ (Figura 9a).

Apesar do maior índice de sustentabilidade obtido para a plantação de tagasaste, é importante notar que a mudança na forma de cultivar, trocando o sistema de rotação tremoço/trigo pelo plantio em ruelas, é benéfica. O plantio em ruelas apresenta índice de sustentabilidade maior que o do sistema de rotação, indicando que esta alternativa pode ser sustentada por períodos maiores. Por outro lado, o sistema de ruelas mostra necessitar de recursos da economia 15\% sej/sej maiores que o sistema de rotação (Fig $9 b)$. O aumento da parcela $F$ reflete-se no valor do rendimento emergético, indicando que apesar de maior índice de sustentabilidade, o sistema de ruelas utiliza os recursos locais com menor eficiência do que o sistema de rotação tremoço/trigo.

Tabela 8: Indicadores emergéticos dos três sistemas de cultivo: rotação tremoço/trigo, tagasaste e cultivo em ruelas.

\begin{tabular}{|l|c|c|c|}
\hline & TREMOÇO/TRIGO & TAGASASTE & RUELAS \\
\hline Recursos renováveis / sej & $2,88 \times 10^{14}$ & $6,26 \times 10^{14}$ & $3,81 \times 10^{14}$ \\
\hline Recursos não renováveis / sej & $9,88 \times 10^{14}$ & $1,24 \times 10^{14}$ & $3,25 \times 10^{14}$ \\
\hline Recursos da economia / sej & $5,84 \times 10^{14}$ & $4,27 \times 10^{14}$ & $5,55 \times 10^{14}$ \\
\hline Emergia total / sej & $1,86 \times 10^{15}$ & $1,18 \times 10^{15}$ & $1,26 \times 10^{15}$ \\
\hline EYR & 3,18 & 2,76 & 2,27 \\
\hline EIR & 0,46 & 0,57 & 0,79 \\
\hline ELR & 5,46 & 0,88 & 2,31 \\
\hline SI & 0,58 & 3,14 & 0,99 \\
\hline
\end{tabular}

Fonte: Lefroy e Rydberg, 2003.

Figura 9: Diagramas emergéticos ternários representando os três tipos de cultivo: (1) rotação anual entre tremoço e trigo, (2) plantação de tagasaste e (3) plantio em ruelas em que se faz a rotação tremoço/trigo em ruelas ladeadas por tagasaste.

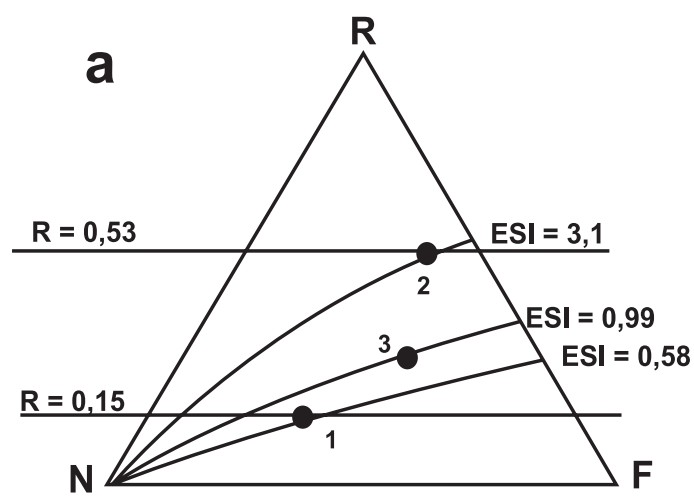

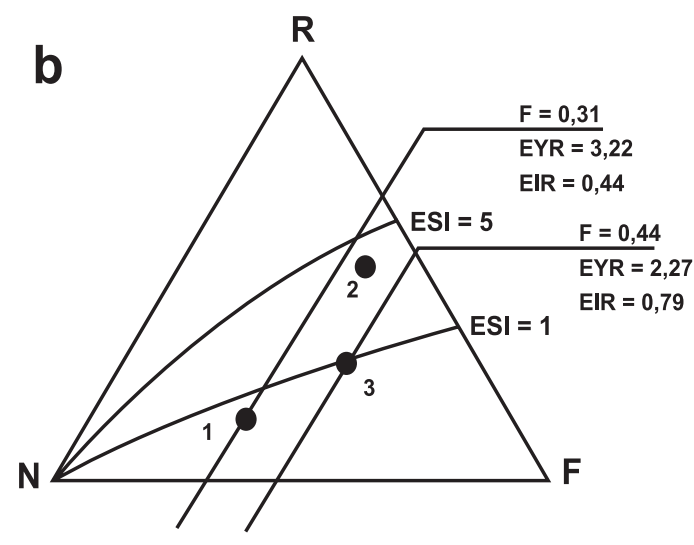




\section{CONCLUSÕES}

A utilização dos diagramas emergéticos ternários permite o melhor entendimento da real contribuição dos recursos do ambiente e da economia para a sustentabilidade de um sistema. Com a observação do diagrama, é possível avaliar e identificar tendências e diferenças para vários sistemas. É, também, possível identificar parâmetros que podem ser mudados para melhorar o desempenho ambiental de um sistema.

identificar os processos com pior ou melhor desempenho ambiental e as áreas em que os investimentos são necessários. Alternativas podem ser simuladas e avaliadas, o que torna esta propriedade do diagrama de grande valia para as tomadas de decisão. Neste contexto, a obtenção do ponto simérgico pode servir de referência para a escolha das melhores alternativas associadas ao meio ambiente e para o estabelecimento de políticas públicas visando a preservação do meio ambiente.

Os diagramas emergéticos ternários podem ser considerados como um progresso quando comparados com métodos que resultam em uma lista de intervenções ou uma representação multi-objetiva. A ferramenta permite a apresentação clara dos resultados, e pode servir de interface entre cientistas ambientais e os responsáveis pela tomada de decisão nos setores produtivos. A adoção dos diagramas emergéticos ternários permite a imediata compreensão tanto das contribuições dos recursos para um determinado sistema,

As propriedades dos diagramas, especialmente as linhas de sensibilidade e o ponto de simergia, complementam a análise emergética e permitem monitorar o desempenho de sistemas ao longo do tempo e acompanhar e/ou simular mudanças nas entradas de recursos com o auxílio dos indicadores definidos pela análise emergética. O uso das linhas de sensibilidade permite identificar, dentre os recursos utilizados por um processo, as mudanças necessárias para elevar o índice de sustentabilidade deste processo, para diminuir a carga ambiental e para avaliar a necessidade de investimento econômico ou de recursos naturais. É possível acompanhar os efeitos de qualquer mudança econômica ou tecnológica e determinar as reais conseqüências destas ações. Por exemplo, pode-se acompanhar o efeito da emergia investida com o uso de uma tecnologia para atenuar emissões por meio do deslocamento do ponto que representa o sistema em estudo no interior do diagrama, como por exemplo a análise mostrada no exemplo 2, que avalia a introdução de Bradhyrizobium japonicum no plantio da soja como inovação tecnológica para fixar nitrogênio no solo. Analogamente, pode-se avaliar a necessidade de serviços ambientais para diluir ou decompor a mesma emissão.

A utilização do ponto de simergia contribui de forma significativa na avaliação de processos, produtos e serviços. Do cálculo do ponto simérgico, levando em consideração a capacidade de produção de cada unidade de um setor, é possível não só avaliar o setor como um todo, mas também como da contribuição do sistema para a sustentabilidade da biosfera.

\section{IMPLICAC̣ÕES}

Apresentando uma base científica sólida, o diagrama emergético ternário é de fácil interpretação, enquanto os métodos correntes empregados e do meio ambiente são frágeis no campo da sustentabilidade. A vantagem da utilização do diagrama ternário associado à análise emergética está no uso da metodologia para estudar diferentes sistemas.

Os resultados apresentados neste trabalho mostram claramente que o emprego do diagrama emergético ternário pelos tomadores de decisão é vantajoso, já que este instrumento permite uma análise articulada e profunda da sustentabilidade ambiental da atividade analisada. Com o conhecimento dos diagramas emergéticos ternários, os tomadores de decisão podem definir ações de melhoria do desempenho ambiental e do monitoramento da evolução temporal de sistemas produtivos, como é requerido pelas recentes normas e regulamentos (ISO 14001, ISO 14040, EIA-RIMA, etc.). Os diagramas emergéticos ternários podem ser úteis para o desenvolvimento de um rótulo específico de ecocompatibilidade/sustentabilidade, para proteger e promover produtos e atividades do mercado e o interesse do administrador e de associações de categorias que podem orientar e proteger o mercado para seus associados. 


\section{Referências}

AZZONE, G.: BERTELE, U. Exploiting green strategies for competitive advantages. Long Range Planning, v. 27, n. 6, p. 69-81, 1997

BARRELLA F. A.; ALMEIDA, C. M. V. B; GIANNETTi B. F. Ferramenta para tomada de decisão considerando interação dos sistemas de produção e meio ambiente. Revista Produção, v. 15, p. $87-101,2005$

BASTIANONI S. A definition of pollution based on thermodynamic goal functions. Ecological Modelling, v. 113, p. 163-166, 998.

BROWN M. T.; ULGIATI, S. Emergybased indices and ratios to evaluate sustainability: monitoring economies and technology toward environmentally sound innovation. Ecological Engineering, v. 9, p. 51-69, 1997 .

Emergy Evaluations and Environmental Loading of Electricity Production Systems. Journal of Cleaner Production, v. 10, p. 21-334, 2002.

BUSICO, A. (Org). Pubblicazione della Presidenza del Consiglio dei Ministri Dipartimento per l'Informazione l'Editoria Direttore: Mauro Mais Stampa e diffusione Istituto Poligrafico e Zecca dello Stato S.p.A. Relatório. Salário, Roma, 2003.

FALCONI-BENITEZ, F. An integrated assessment of changes in land-use in Equador. In: ULGIATI, S. (Ed.). Advances in Energy Studies, v. 2. Porto Venere, Italy: SGE Editoriali, p. 409-421, 2000.

GERBENS-LEENES P. W; NONHEBEL, S Resource use efficiencies in primary production systems: comparison between two disciplines. In: ULGIATI, S (Ed.). Advances in Energy Studies, v. 2. Porto Venere, Italy: SGE Editoriali, p. 235-242, 2000
GIAMPIETRO, M.; MUNDA, G. Integrated assessment of complex adaptative systems: an overview of epistemologica challenges. In: ULGIATI, S. (Ed.). Advances in Energy Studies, v. 2. Porto Venere, Italy: SGE Editoriali, p. 305-318, 2000

GIANNANTONI, C.; MIRANDOLA, A.; TONON, S.; ULGIATI, S. (2002) Energybased, Four-sector diagram os benefits as a decision making tool. In: ULGIATI, S. (Ed.). Advances in Energy Studies, v. 3 Porto Venere, Italy: SGE Editoriali, p. 575-586, 2002.

GIANNETTI, B. F.; BARRELLA, F. A. ALMEIDA, C. M. V. B. A combined too for environmental scientists and decision makers: ternary diagrams and emergy accounting. Journal of Cleaner Production, 2005. No prelo, disponível em: www. sciencedirect.com desde dezembro de 2004.

GOMIERO, P.; GIAMPIETRO, M. Multiobjective integrated representation (putting in perspective biophysical analyses) applied to aquaculture. In: ULGIATI, S. (Ed.). Advances in Energy Studies, v. 3. Porto Venere, Italy: SGE Editoriali, p. 187-199, 2002a.

Multiple-scale assessment of farming systems in Upland Vietnam. In: ULGIATI, S. (Ed.). Advances in Energy Studies, v. 2. Porto Venere, Italy: SGE Editoriali, p. 465-482, 2000b.

HOFSTETTER, P.; BRAUNSCHWEIG A.; METTIER T ; MÜELLER-WENK, R . TIETJE $O$. The mixing triangle: Correlation and graphical decision support for LCA-based comparisons. Journal of Industrial Ecology. v. 3 , n. 4 , p. $97-115,2000$

JALAL, K. F.; ROGERS, P. P. Measuring environmental performance in Asia. Ecological Indicators v. 2, n. 1, p. 39-59, 2002.
JONSSON, A. Tools and methods for environmental assessment of building products- methodological analysis of six selected approaches. Building and Environment, v. 35, p. 223-238, 2000.

LEFROY, E.; RYDBERG, T. Emergy evaluation of three cropping systems in southwestern Australia. Ecological Modelling, v. 161, n. 3, p. 195-211, 2003

MARADAN, D. PILLET, G : NIEDERHAUSERZINHH, N. Appraising externalities of the Swiss agriculture: a comprehensive view. In: ULGIATI, S. (Ed.). Advances in Energy Studies, v. 2. Porto Venere, Italy: SGE Editoriali, p. 501-512, 2000.

MAXWELL J. et al. Green schemes: corporate environmental strategies and their implementation", California Management Review, v. 39, n. 3, p. 11834, 1997.

ODUM, H. T. Environmental Accounting - Emergy and Environmental Decision Making. Nova York: Ed. John Wiley \& Sons Ltd, 1996.

PANZIERI, M. Analisi ed indagine termodinamica di sistemi complessi. M.Sc. Thesis, 1995. University of Siena, Italy.

PANZIERI, M.; MARCHETTINI, N. HALLAM, T G. Importance of the Bradhyrizobium japonicum symbiosis for the sustainability of soybean cultivation. Ecological Modeling, v. 135, p. 301-310, 2000

PORTER, M.; LINDE VAN DER C. Green and Competitive Harward Business Review, p. 120-134, set-out, 1995a.

Toward a new conception of the environment competitiveness relantionship, Journal of Economic Perspectives, v. 9, n. 4, p. 97-118, 1995b.
RONCHI, E; FEDERICO, A.; MUSMECI, E A system oriented integrated indicator for sustainable development in Italy. Ecological Indicators, v. 2, p. 197-210, 2002.

SARKIS, J. "Manufacturing strategy and environmental conciousness". Technovation, v. 15, n. 2, p. 79-97, 1995.

SEPPÄLÄ J.; HÄMÄLÄINEN R. P. On the Meaning of the Distance-to-Target Weighting Method and Normalisation in Life Cycle Impact Assessment. International Journal LCA, v. 6, n. $4, \mathrm{p}$. 211-218, 2001.

SHEN, T. T. Industrial Pollution Prevention, Berlin: Springer-Verlag, 1995.

SHU-LI, H. Urban ecosystems, energetic hierarchies, and ecological economics of Taipei metropolis. Journal of Environmental Management. v. 52, n. 11, p. 39-51, 1998

TONON, S, et al. Integration os thermodynamic, economic and environmental parameter for the evaluation of energy systems. In: ULGIATI, S. (Ed.) Advances in Energy Studies, v. 2. Porto Venere, Italy: SGE Editoriali, p. 635-647, 2000.

ULGIATI, S.; BROWN, M. T. Monitoring patterns of sustainability in natural and man-made ecosystems. Ecological Modeling, v. 108, n. 1, p. 23-36, 1998.

Quantifying the environmental support for dilution and abatement of process emissions - The case of electricity production. Journal of Cleaner Production, v. 10, n. 4, p. 335$348,2002$.

ULGIATI, S. et al. Emergy-based indices and ratios to evaluate the sustainable use of resources. Ecological Engineering, v. 5 , n. 4, p. 519-531, 1995.

\section{Agradecimentos}

Os autores agradecem o apoio da Vice Reitoria de Pós-Graduação e Pesquisa da Universidade Paulista. Um agradecimento especial é endereçado ao Dr. Corrado Giannantoni (National Agency for New Technology, Energy and the Environment - Energy Department, Research Centre of Casaccia, Roma, Itália) por seus comentários. 
- Sobre os autores

Biagio F. Giannetti

Universidade Paulista - UNIP

Prof. Dr. dos cursos de mestrado e doutorado de Engenharia de Produção

Produção e Meio Ambiente - Produção mais Limpa e Ecologia Industrial. End.: Rua Dr. Bacelar, 1212 - LaFTA - São Paulo - SP - CEP 04028-002

Tel.: 1155864127

E-mail: biafgian@unip.br

\section{Flávio A. Barrella}

Universidade Paulista - UNIP

Mestre em Engenharia de Produção

Produção e Meio Ambiente - Produção mais Limpa e Ecologia Industrial.

End.: Rua Lenine Severino, 89 - São Paulo - SP - CEP 05353-230

Tel.: 1137146992

Cel.: 1199489885

E-mail: flavio.barrella@uol.com.br

\section{Silvia H. Bonilla}

Universidade Paulista - UNIP

Profa. Dra. dos cursos de mestrado e doutorado de Engenharia de Produção Produção e Meio Ambiente - Produção mais Limpa e Ecologia Industrial. End.: Rua Dr. Bacelar, 1212 - LaFTA - São Paulo - SP - CEP 04028-002 Tel.: 1155864127

E-mail: bonilla@unip.br

\section{Cecília M. Villas Boas de Almeida}

Universidade Paulista - UNIP

Profa. Dra. dos cursos de mestrado e doutorado de Engenharia de Produção Produção e Meio Ambiente - Produção mais Limpa e Ecologia Industrial. End.: Rua Dr. Bacelar, 1212 - LaFTA - São Paulo - SP - CEP 04028-002 Tel.: 1155864127

E-mail: cmvbag@unip.br 